\title{
Is intuition associated with ethical decision-making?
}

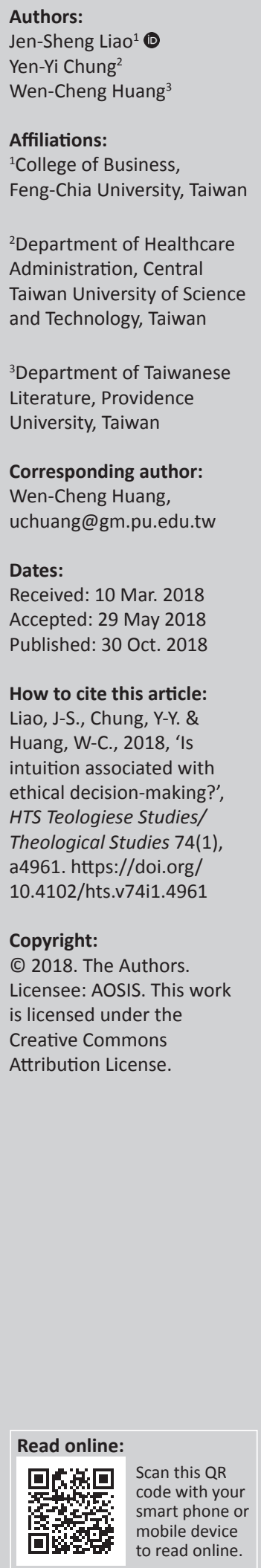

\section{Authors:}

Yen-Yi Chung

Wen-Cheng Huang ${ }^{3}$

Affiliations:

${ }^{1}$ College of Business,

${ }^{2}$ Department of Healthcare

Administration, Central

Taiwan University of Science

${ }^{3}$ Department of Taiwanese

Literature, Providence

University, Taiwan

Corresponding author:

Wen-Cheng Huang,

Dates:

Received: 10 Mar. 2018

Accepted: 29 May 2018

How to cite this article: Liao, J-S., Chung, Y-Y. \& Huang, W-C., 2018, 'Is intuition associated with HTS Teologiese Studies/ Theological Studies 74(1), a4961. https://doi.org/

Copyright:

(C) 2018. The Authors. is licensed under the

Creative Commons

Attribution License.
The relationship between intuition and ethical decision-making has been researched extensively during the past two decades. This study aimed at exploring empirically observable associations between intuition and the moral intensity of ethical decision-making processes. A scenario-based quantitative approach was used to collect data from 157 practising professional spirit mediums. It was found that only collective universal intuition had a significant positive association with the moral intensity of ethical decision-making processes. Personal experience intuition and collective archetype intuition were not significantly associated with moral intensity. This may explain why previous studies were unable to gauge the effects of intuition on ethical decision-making. The results suggest that a pure mind can improve one's ability to make decisions. Thus, decision-makers would benefit by being more attuned to their sense of morality.

\section{Introduction}

\section{Background}

Intuition has been found to considerably influence how people react to judgements (Dutton 2010). Intuition was defined by Jung ([1923] 1921) as:

the function that mediates perceptions in an unconscious way. Everything can be the focus of this perception, outer or inner objects, or their relationships ... it is neither sense perception, nor feeling, nor intellectual inference, although it may also appear in their forms. (p. 462)

Rationalist researchers have suggested that moral decisions are usually based on deliberate reasoning (Becker 1976; Jones 1991; Kohlberg 1971; Rest 1986). Jones (1991) provided one of the most popular and significant rationalist theoretical models of ethical decision-making (EDM), which not only consolidated previous theoretical models such as Rest's (1986) but also introduced the factor of 'moral intensity (MI)' to ethical issues.

Following decades of rationalist dominance under the auspices of a cognitive paradigm (Kohlberg 1971), moral psychology has turned towards emotion and intuition in studying decisions and decision-making (Ellertson, Ingerson \& Richard 2016; Haidt 2001; Schwartz 2016; Sonenshein 2007). According to Haidt's (2001) social intuitionist model, moral judgements are caused by rapid moral intuitions, which are accompanied by post-hoc moral reasoning. Sonenshein (2007) also argues that people facing an ethical issue make intuitive judgements instantaneously and that these judgements are followed by explanations and justifications. Therefore, as Mikhail (2007) states, it is necessary to build on the models and arguments that accord intuition an important role in EDM processes.

The nature of the interplay between intuition and Jones's 'MI' is yet to be determined. Kahneman (2003) stated that intuition typically operates in a fast, automatic, effortless, associative and often emotionally charged manner. Monin, Pizarro and Beer (2007) argue that intuition may be thought of as a behavioural guide or an evaluation that immediately follows an emotional experience. However, according to Jones's issue-contingent perspective, high MI leads to higher levels of cognitive moral development, which, in turn, results in a greater number of moral intentions and actions. Unconscious intuition may also influence MI, which drives unconscious moral intent. In other words, MI can be an intermediary between moral intuition and moral action.

\section{Trends}

Although these studies claim that we arrive at moral verdicts on the basis of our emotionally charged intuitions, there is not enough evidence to state that intuitions are indeed involved in 
EDM processes (Ayoun, Rowe \& Yassine 2015; Tinghög et al. 2016). Moreover, moral judgements and actions are likely to be influenced by processes that are largely unconscious; therefore, it is difficult to determine what really drives moral behaviour (Sauer 2012). Arnold, Goodpaster and Weaver (2016) contend that research on ethical behaviour is fraught with limitations. In particular, they argue that the normative perspective of these studies is mostly limited to Western morality and that studies regarding empirical and normative business ethics typically focus on either isolated individuals or group actor(s) in large corporations.

To overcome these research limitations, the present study focuses on spirit mediums (as a special sample) to provide a new perspective. Working with knowledge and particularly with mixed intuition and symbolic shorthand often leads to the awakening of mediumship (Tribodeau 2009). Assisted by rigorous religious training, spirit mediums may have attained higher levels of consciousness when compared with ordinary people. Spirit mediums utilise their special psychic abilities to interact with spirits and deities. This interaction is marked by the use of special language, dance and what may be magic spells to eliminate evils and seek blessing. Spirit mediums can also sense the power of the spirits that they interact with.

\section{Purpose}

The purpose of this research is to determine whether intuition is associated with the MI involved in EDM, thereby adding to the body of knowledge on EDM. Drawing from Jung's classification of the unconscious, this article divides intuition into three types: personal experience intuition (PEI), collective archetype intuition (CAI) and collective universal intuition (CUI). In addition, the article also explores the relationships of MI with (1) moral recognition, with (2) moral judgement and with (3) moral intention in Jones's issue-contingent model.

\section{Contribution to field}

Mediumship is a specific form of knowing that allows it to be extended on behalf of others (Clart 2003; Sutton 1989; 1990; 2003; Tribodeau 2009; Zheng 2016). For this research, 200 Taiwanese spirit mediums were contacted, and the findings can help to enrich our understanding of intuition and moral judgement. In addition, the inclusion of non-students and non-managers ensures that the findings are generalisable. In cases where there exist systematic differences, this can serve to flesh out our understanding of earlier, biased studies (Henry 2008; Peterson 2001; Sears 1986).

\section{Literature review}

\section{Theoretical descriptive ethical decision-making approaches}

Three general EDM theoretical models have been proposed in previous research: (1) rationalist, (2) non-rationalist and (3) integrated. Although rationalist approaches have tended to include the notion that intuition or emotion might play a role in EDM, they do not consider moral intuition to be a determination of moral judgement (Schwartz 2016). Nonrationalist approaches, in contrast, do hold that moral intuition influences moral judgement (Haidt 2001). Integrated approaches suggest that there is a concurrent interaction between intuition (impulsive) and reason (reflective) when moral judgements are made (Schwartz 2016).

\section{Rationalist approach}

The rationalist approach suggests that when faced with an ethical dilemma, the decision maker attempts to resolve the conflict using a logical, rational and deliberative cognitive process (Schwartz 2016). Trevino (1986) introduced a personsituation integrationist model for EDM, which began by suggesting that the manner that an ethical dilemma is analysed by a decision maker depends upon the individual's stage of cognitive moral development (Kohlberg 1973). The decision maker's initial cognition regarding right and wrong is then moderated by individual factors such as ego strength, field dependence and locus of control.

Rest (1986) posited that there are four distinct process components (or stages) in EDM: (1) becoming aware that there is a moral issue or ethical problem or that the situation has ethical implications (also referred to as recognition); (2) leading to a moral judgement (also referred to as EDM); (3) establishing a moral intent (also referred to as moral motivation); and (4) acting on these intentions through one's behaviour (also referred to as the action). The moral judgement stage of Rest's model, which was seen as a key moral reasoning component of the EDM process, was based on Kohlberg's (1971; 1973) rationalist theory of moral development (Schwartz 2016).

Building on and consolidating Rest's model, Jones (1991) provided an important contribution to EDM theory by introducing the issue-contingent model. This model included the important new factor of ' $\mathrm{MI}$ ', which considered consequences, social consensus and proximity, or the feeling of nearness. The MI of an issue can influence the EDM stages and can act as both an independent variable as well as a moderating one.

In addition, Jones (1991) presented four propositions: firstly, issues of high MI would be recognised as more frequent moral issues; secondly, issues of high MI would elicit higher levels of cognitive moral development, which would strongly influence moral judgement (Trevino 1986); thirdly, moral intent would be established more frequently when issues of high MI were involved; and fourthly, moral action would be observed more frequently when issues of high MI were involved.

\section{Non-rationalist approach}

According to the non-rationalist approach, intuition and/or emotion or sentiments are central to the EDM moral judgement process. Some models have placed deliberative reasoning after flashes of intuition or perceptions (e.g. Bargh 2005; Haidt 2001); some others have put rationality before 
emotion as a type of unconscious reasoning that produces intuition (e.g. Sustain 2005), and others still have seen intuition as a type of reasoning itself (e.g. Gigerenzer 2008). Despite this variety of views, however, researchers are generally in agreement that there is an element of automaticity (whether it is labelled emotional, intuitive or perceptive) in moral judgements.

Haidt's (2001) social intuitionist model described two principal attributes: (1) moral judgement is generally the result of quick moral intuitions, and (2) moral judgement is significantly affected by social and cultural influences. In this model, the moral agent is moral intuition, which is a type of spontaneous evaluation 'at the fringe of consciousness', and while it does not involve a direct evaluation or a critical weighing up of evidence, it can have a meaningful influence on ethical judgements and subsequent decision-making (Haidt \& Bjorklund 2008).

This work was extended in Sonenshein's (2007) sensemaking-intuition model, which integrated social psychological moral judgement theories (Haidt 2001) and Weick's (1995) theory of sense-making. In Sonenshein's model (2007), EDM has three phases: issue construction, intuitive judgement and explanation and justification. Presented with stimuli from a context with a high degree of ethically relevant uncertainty (e.g. a potential ethical dilemma), individuals engage in ethical issue construction, a process of sense-making (Weick 1995) by which they attempt to interpret the situation they are facing. Reaching a plausible interpretation of the situation, individuals then engage in an instantaneous and effortless intuitive judgement that is based on moral intuitions that have been shaped by their own experiences and social pressure. Subsequently, they explain and justify their judgements to themselves (and potentially, to others) through conscious moral reasoning.

\section{Integrated approach}

Integrated approaches suggest that the two systems (reasonrationalisation and intuition-emotion) operate together and are both involved in moral judgements. Vasconcelos (2009) attempted to demonstrate that both forms of the decisionmaking process (e.g. rational and non-rational analysis) coexist perfectly in an integrative frame that takes prayer before intuition and concluded that this religion-based framework probably enables decision-makers to avoid injustice, attract good spiritual influences, repel bad spiritual influences and enhance the accuracy of their final decisions.

\section{Definition of intuition}

Previous studies have defined intuition as a function that is beyond reasoning, the purely physical, the cognitive or even the emotional. For example, Barnard (1938) considered intuition to be an unexplainable phenomenon. Barnard considered that the intuitive process was grounded in knowledge and experience and was activated unconsciously or without any conscious effort. Simon (1992) argued that the term 'intuition' was a rapid problem-solving or questionanswering performance, the reasoning for which could not be described in detail. Within this perspective, intuition, therefore, was seen as an outcome of an expert's rapid recognition of a situation that was marked by familiar cues.

Jung believed intuition had three functions (Marshall 1968). Firstly, intuition is concerned with relationships and wholes (Jung 1921 [1923]:568, 1936 [1936]:123-124). Secondly, intuition perceives complete wholes, which can include not only the immediate sensory elements but also invisible, past, future or potential elements (Jung 1921 [1923]:463). Thirdly, intuition is that psychological function which transmits perceptions in an unconscious way (ibid.:5). It is likely that Jung was inferring that the mechanisms underlying intuition are more unconscious and can be concerned with the collective unconscious (Marshall 1968).

\section{Hypotheses}

\section{Three types of intuition and moral intensity}

Empirical studies have shown that two components of MI, namely, social consensus and magnitude of effect, frequently influence moral attitude (Shaw 2003) and moral judgement (Valentine \& Fleischman 2003). Ayoun et al. (2015) explored the association between spirituality and ethics by testing the correlation between spirituality and each of the three moral intensities (magnitude of consequence, social consensus and probability of effect). Hence, the effort to identify individual and organisational factors that impact moral judgement has been partly successful. In exploring intuition in relation to EDM, this article tries to link the MI and intuition that have been validated in the literature.

Personal experience intuition: The personal unconscious, located at the fringe of consciousness between two worlds, the exterior or spatial world and the interior or psychically objective world (Ellenberger 1970), consists of complexes and an individual's experience (Jung 1981). A complex can be imagined as a knot of unconscious feelings and beliefs that is indirectly detectable through behaviour that is puzzling or difficult to explain (Sultania et al. 2012). Therefore, the personal unconscious is an organ of thought that has been developed from the results of thinking. The personal unconscious first wills and then discriminates and judges. As to judge is to divide, this division ends in a dual view of existence (such as right or wrong and good or bad). Because willing and thinking are inextricably woven into the texture of a person's unconscious, the personal unconscious plays an important role in the evaluation and assessment of meaning and morality. Intuition from the personal unconscious has been labelled PEI. Because complexes are concealed but affect the personal unconscious, when a person makes an intuitive judgement, personal unconscious intuition may not encompass all the possibilities of whole relationships to make a suitable judgement. Thus, this article proposes the following hypothesis:

- Hypothesis 1: Personal experience intuition is not associated with MI. 
Collective archetype intuition: The archetype is one element of the collective unconscious. Archetypes refer to the unclear underlying forms from which images and motifs such as the mother, the child and the trickster emerge. History, culture and the personal contexts that shape these manifest representations, therefore, imbue them with their specific content (Jung 1981). The shadow archetype is seen as a human's dark side (Young \& Dawson 1997). Jung (1969) thought that the shadow was a moral problem that challenged the ego personality. Although the top layers of this shadow contain a meaningful flow and manifestation of direct personal experiences, underlying these idiosyncratic layers are the archetypes that form the psychic content of all human experiences (Campbell 1971). Jung referred to this bottom layer of the shadow as the collective unconscious, which, while originally immaculate in itself, contains a mysterious mixture of purity and defilement and good and evil. The intuition from this collective unconscious is labelled CAI. Because the shadow is so minutely subtle and influences the collective unconscious, when a person makes an intuitive judgement, CAI may lose the ability to transmit a mythological image perception. Accordingly, this article proposes the following hypothesis:

\section{- Hypothesis 2: CAI is not associated with MI.}

Collective universal intuition: Another component of the collective unconscious is the universal image from which arises CUI (Ruff 2000), which, while seen as essential, is also the most far-fetched mythological motif and symbol (Jung 1981). CUI has been regarded as immaculate and pure and is similar to the intellectual intuition of Kant (1790 [1952]), who stated that intellectual intuition 'is not an empirical fact, but the sole fact of the pure reason, which thereby announces itself as originally legislative'. Therefore, when a person is faced with an ethical judgement, universal collective intuition may be harnessed to make the moral judgement because it accesses the three intuitional functions for the awareness of relationships, encompassing the greatest possibilities and transmitting mythological images. Thus, this article proposes the following hypothesis:

- Hypothesis 3: CUI is positively associated with MI.

Jones's issue-contingent model: The construct of moral intensity refers to the 'extent of issue-related moral imperative in a situation' (Jones 1991:372). MI is a multidimensional construct that contains various facets. This implies that the greater the MI of any given ethical situation and the higher the level of an individual's ethical awareness, the more likely that person is to render an ethical judgement. Further, the greater the level of an individual's ethical intent, the more likely that individual is to exhibit ethical behaviour. Jones argued that any issue can be represented in terms of its MI. MI, moreover, may vary with each issue. The following hypotheses have been formulated on the basis of these statements:

- Hypothesis 4.1: MI is positively associated with moral recognition.
- Hypothesis 4.2: MI is positively associated with moral judgement.

- Hypothesis 4.3: MI is positively associated with moral intentions.

\section{Materials and methods}

\section{Samples}

Questionnaires were distributed to 200 spirit mediums initially. After 43 incomplete questionnaires were eliminated, a total of 157 participants successfully took part in the study. Unlike previous studies that used students or managers as samples, this study took special spirit mediums as subjects. The reasons are as follows:

Firstly, a medium is a person who can communicate with the soul of the dead in spiritualist sessions. The function of intuition in the intermediary state unites mediums with intermediary beings (Pilard 2015). As a spirit medium's experience can help in understanding the unconscious and human psychology, the spirit medium has become a more common subject in recent psychology research (Shamdasani 2009). Secondly, Fontein (2006) believed that spirit medium performances also involve 'responding to, and engaging with, the social, political, and moral expectations of those around them'. Thirdly, mediums face many potential ethical concerns in their work, such as people's need for protection or the pursuit of material gains (Tsai 2004). Fourthly, mediums assert that they channel gods directly (Cline 2010:547). This is in line with the third intuition type (i.e. CUI). The role of a spirit medium is similar to that of a shaman. A shaman is capable of communicating with the dead, the demons and nature deities or spirits without, however, becoming their instrument or being taken over by them (Groesbeck 1989). Most significantly, a shaman, as an individual healer, can use his or her spirit to travel to other worlds to find and restore a patient's lost soul (Eliade 1964).

How does a person become a spirit medium? Field researchers are quick to highlight the seemingly involuntary character of the process. It has been noted that prospective mediums typically suffer seizures, hallucinations or strange ailments, and these are interpreted as a deity's call - a call demanding the individual's surrender (Clart 2003). In addition, to become a skilled medium, it is necessary for one to develop the faculties essential to communicate with spirits (Tsai 2004).

Spirit mediums use their special psychic ability to interact with spirits. Their interaction with gods and demons is marked by the use of special language, dance and magical spells, which are aimed at eliminating evil and seeking blessing. The spirit world, moreover, is not controlled by a single god; it is characterised by infinite incarnations and boundaries, which generate a special cosmology of the spirit world (Zheng 2016). However, the literature on this subject does not mention or provide details about the various deities. Significant studies of Taiwanese spirit mediums include Sutton $(1989 ; 1990 ; 2003)$, Paper $(1995 ; 1996)$ and Clart (2003). 


\section{Setting}

This study does not use the 'trolley problem' or any of its variants, which are otherwise prominently used in moral psychology research (Foot 1967). Instead, a scenario involving an extramarital affair was devised for the purposes of this research. There are several reasons for doing so:

1. Extramarital affairs are illegal in Taiwan, according to Article 239 of Taiwan's Criminal Code, with both parties to adultery subject to punishment.

2. In recent years, the Taiwan Judicial Reform Foundation has repeatedly proposed decriminalising 'adultery', pointing out that the feelings of the couple cannot be resolved by law and that the decriminalisation of adultery is a worldwide trend.

3. Spirit mediums in Taiwan are mainly consulted for matters involving extramarital affairs. Consequently, mediums face an ethical dilemma in these situations, given their belief in the principle of karma. Moreover, it is not possible or feasible for them to take a moral stance on the people involved in the affair.

4. The Chairman of the Taiwanese Medium Association also confirmed the relevance of this scenario for the present study.

5. The 'trolley problem' is more suitable to utilitarian ethics, which seeks to maximise the happiness of the greatest number of people (Barbour 2014). However, Taiwanese spirit mediums regard all lives equally.

The results of the survey indicate that the mean perceived ethical problem (moral recognition) score for this scenario was 3.81 on a five-point Likert scale, which indicated that participants generally saw the scenario as an ethical problem. This finding is similar to those gleaned from the results reported by Singhapakdi, Vitell and Kraft (1996), who found that mean responses ranged from 6.25 to 8.42 on a nine-point Likert scale.

\section{Design and measure}

This survey involved the use of a questionnaire to assess the following parameters: PEI, CAI, CUI, MI, moral recognition, moral judgement and moral intention (see Appendix 1). All 18 items in this questionnaire were measured on a five-point Likert scale: disagree strongly (1); disagree (2); not certain (3); agree (4); and agree strongly (5). There were several reasons for using a five-point Likert scale. Firstly, Morris and McDonald (1995) used a five-point Likert scale to explore the role of MI in moral judgement for their experiment. This study replicated their research and endeavoured to compare results. Secondly, with a five-point scale, it is quite simple for the interviewer to read out the complete list of scale descriptors (Dawes 2008). Thirdly, a five-point scale was used to increase response rate and response quality along with reducing respondents' 'frustration level' (Babakus \& Mangold 1992). Questions were given in logical order. The scenario was presented after PEI, CAI and CUI. Following the scenario, there were eight items related to moral recognition, moral judgement, $\mathrm{MI}$ and moral intention. This logical order method is the same as Fu and Yen's (2002) in their study on marketing EDM:

- PEI, CAI and CUI were measured using three or four items (see Appendix 1). Clairvoyance was adopted for CUI on the basis of Jung's belief that it was a type of supernatural perception (Lecture IX 15 December 1933). Jung distinguished between two levels of clairvoyance. The first was the capacity to see or hear things that were normally beyond a clairvoyant's perception; therefore, this level would include the clairvoyant's ability to see or hear entities such as spirits of the dead, angels and demons. The second level pertains to the capacity to access ultimate realities (Pilard 2015).

- Moral intensity: Jones (1991) argued that any issue can be represented in terms of its MI. In the present study, MI was measured using a method similar to the one employed by Singhapakdi et al. (1996). Five of the six original components of the proposed construct developed by Jones (1991) were relevant for the purposes of this study. The five components were the magnitude of consequences (defined as the sum of harms or benefits to victims or beneficiaries of the moral act in question); the social consensus (defined as the degree of social agreement regarding whether a proposed act is evil or good); the probability of effect (defined as a joint function of the probability that the act in question will actually take place and that the act in question can actually cause harm or benefit); the temporal immediacy (defined as the duration between the present and the onset of the consequences of the moral act in question); and the proximity (defined as the feeling of nearness - social, cultural, psychological or physical - that the moral agent has to victims or beneficiaries).

- These five items were combined to form a single perceived MI measurement for analysis as the selected items served as an approximation of the full perceived MI construct. Jones (1991) also suggested that MI items might have interactive effects, which would be expressed in the combined measurement.

- Moral recognition: The recognition of a moral issue in a situation is referred to as an ethical perception (Jones 1991). A person who does not recognise an ethical issue tends to use criteria other than ethical schemes when making decisions (Jones 1991). This study checked the mean moral recognition score of all respondents to verify that the respondents (as a group) perceived the situation as an ethical problem (see also Singhapakdi et al. 1996).

- Moral judgement: Moral judgement is an individual's personal evaluation of the ethicality of a behaviour (Sparks \& Pan 2010). Both moral recognition and judgement precede moral intent (Hunt \& Vitell 1986), or a decision is made to act on the basis of moral judgement (Jones 1991). The main benefit of the moral judgement item is that it allows a second rating of moral recognition that detached the respondent from the situation, thereby reducing the bias towards the socially desirable answer (Kennedy \& Lawton 1998). 
- Moral intention: This parameter was also drawn from Jones (1991); this is used to differentiate moral perceptions and judgements from moral intention. In other words, moral judgement was not seen to automatically lead to a corresponding action.

All three variables (moral reorganisation, moral judgement and moral intent) were measured by one item as did similar previous empirical studies by Morris and McDonald (1995), Singhapakdi et al. (1996), and Fu and Yen (2002). The three items were then combined to form one variable (i.e. ethical decision process) to fulfil the structural equation model (SEM) requirement.

\section{Procedure}

Members of the Taiwanese Medium Association, founded in 1989, were contacted and invited to participate in the survey. The assistance of the Taiwanese Medium Association allowed the researcher to reach a population that was both widely dispersed geographically and difficult to reach through conventional survey methods. Similar to the sampling performed by Giacalone and Jurkiewicz (2003) and Ayoun et al. (2015), snowball sampling was used as this technique has often been employed on hidden populations that are difficult for researchers to access. To ensure that a good sample was obtained, the initial survey distribution specifically targeted the Taiwan Medium Association so as to start with the snowball sampling of the focused population. Any surveys forwarded to expand the sample, therefore, had a good chance of reaching the valid respondents as the target population was diverse enough (spread throughout Taiwan) to accommodate minor dissemination variations. As an extra precaution, a survey question requested for the respondent's job title to ensure that the person targeted was a top-level spirit medium. Another benefit of snowball sampling is that it is expected to encourage participation. A survey that measures sensitive subjects such as spirituality and ethics may be better received through a friend or familiar colleague than it may be through someone unknown. The snowball sample in the present study initially reached 200 spirit mediums, of which 157 valid responses were received. This response rate is $78.5 \%$ (157 out of 200). The number of respondents compared favourably with other studies related to ethics. For example, Guzak (2009) recruited 294 participants, and a study by Ayoun et al. (2015) was able to recruit 165 active participants (a response rate of $23 \%$ ).

Details regarding how many mediums were initially contacted by the researchers and how many respondents were involved consequent to this request as opposed to requests made by friends are not mentioned as these do not fall within the scope of this research.

\section{Analysis}

The data were analysed using SPSS reliability, correlation and regression analyses. In addition, the SEM and the rival model were also used to test the validity and the model's fit.
The use of the SEM is commonly justified in the social sciences, given its ability to impute relationships between unobserved constructs (latent variables) of observable variables (Loehlin 2004). Table 1 shows the idea value of the model fit index in the SEM. In addition, once a researcher is confident that a plausible hypothesis supports the inferred relationship, they must then rule out the plausibility of rival hypotheses and models (Campbell \& Stanley 1963). If the model survives up to this point, it may be reasonable to conclude, probabilistically, that a causal relationship has been demonstrated (McCoach, Black \& O'Connell 2007).

Moreover, Loehlin (2004) and Kline (2011) state that at least 100 responses ought to be generated to meet the minimum requirements of the SEM. The current study generated 157 responses.

\section{Ethical considerations}

Items in the questionnaire were created in accordance with previous studies (see Appendix 1). The questionnaire was designed to preserve participants' anonymity. Participation was voluntary, and participants were informed that they had the right to refrain from answering specific questions or to withdraw at any time. The participants were also told that the results of this study might be published in professional and/ or social journals. They were also informed that the results could be used for other educational purposes. They were assured that their anonymity would be maintained at all costs.

The participants in this questionnaire are anonymous. The questionnaire was approved by the College of Business in Feng-Chia University (No. 20111018P9945756).

\section{Results \\ Reliability and validity \\ Reliability}

All measures were analysed for reliability and validity. Appendix 1 shows the measure characteristics and sample measurement items. For internal consistency reliability, Nunnally (1978) and Hair et al. (1992) suggested that Cronbach's $\alpha$ is considered to be highly reliable if the $\alpha$ value is between 0.7 and 0.98; that the research can regarded as significant if the $\alpha$ value is above 0.5 ; and that the research should be rejected if the $\alpha$ value is under 0.35 .

TABLE 1: Idea value of model fit index.

\begin{tabular}{llc}
\hline Model fit index & Index full name & Idea value \\
\hline$\chi^{2}$ & - & Smaller is better \\
$\chi^{2} / \mathrm{df}$ & - & $1-5$ \\
GFI & Goodness-of-fit index & $>0.8$ \\
AGFI & Adjusted goodness-of-fit index & $>0.8$ \\
PNFI & Parsimony-adjusted normed fit index & $>0.5$ \\
CFI & Comparative fit index & $>0.9$ \\
RMR & Root mean square residual & $<0.08$ \\
RMSEA & Root mean square error of approximation & $<0.08$ \\
\hline
\end{tabular}

Source: Bollen, K.A. \& Long, J.S., 1992, 'Tests for structural equation models', Sociological Methods and Research 21(2), 123-131. https://doi.org/10.1177/0049124192021002001 
Cronbach's $\alpha$ value was found to be 0.801 for PEI, 0.519 for CAI, 0.686 for CUI and 0.743 for MI, with Cronbach's $\alpha$ for all 18 items being 0.759 ; therefore, the results from the PEI and MI were considered to be highly reliable. The CAI and CUI had lower alpha values (0.519 and 0.686). However, as these were also above the 0.5 standard value, the results were considered to be reliable.

\section{Validity}

- Content validity: This article is based on relevant and credible references. Experts in mediumship were consulted both to formulate the pre-test and to chart the questionnaire.

- Face validity: Face validity is the extent to which a test is subjectively viewed as covering the concept it purports to measure. To obtain face validity, the researchers obtained confirmation from the chair of the Taiwan Medium Association (Mr Gao Tien-Wun) to ensure that the proposed scenario (an extramarital affair) was a suitable ethical dilemma for investigating EDM. Thus, the appropriateness of this population has been verified.

- Composite reliability: Confirmatory factor analysis (CFA) was used to test validity. Boomsama (1982) and Loehlin (2004) suggested that the minimum sample size should be at least over 100. Ding, Velicer and Harlow (1995) believed that 100-150 samples are the basic requirement for SEM. Because our sample size is 157, it is eligible for testing the validity by using CFA with no doubt:

- The composite reliability (CR) values for PEI, CAI, CUI and MI were, respectively, 0.805, 0.534, 0.824 and 0.756. For social science, Raines-Eudy (2000) mentioned that the measure instrument can get the basic stability when the CR is more than 0.5 . Because all the CRs were over 0.5, this research had good construct validity.

- Factor loading: Factor loading was required to be above 0.3 (Vizczino et al. 2010). Questions with factor loading less than 0.3 do not have the characteristic consistency of the questionnaire and thus should be deleted (Shyu, Li \& Tang 2013). Because our factor loadings of all items were over 0.3 , we kept all items.
- KMO and Bartlett's Test: The Kaiser-Meyer-Olkin (KMO) measure of sampling adequacy indicates the proportion of variance in the variables that might be caused by underlying factors. High values (close to 1.0) generally indicate that factor analysis may be useful with data. If the value is less than 0.50 , the results of the factor analysis would probably not be very useful (Sharma 1996). In the current research, the KMO is 0.733, which means that our sampling (157 responses) is adequate.

Bartlett's test of sphericity assesses the hypothesis that a correlation matrix is an identity matrix, which would indicate that the variables are unrelated and therefore unsuitable for structure detection. Small values (less than 0.05) of the significance level indicate that a factor analysis may be useful with the data. In the present study, Bartlett's test is significant, with the approximate Chi-square being 828.250 and $\mathrm{df}$ being 136 . This means that our sampling is eligible for factor analysis.

\section{Correlation}

The variables for the three kinds of intuition (PEI, CAI, CUI), MI, moral recognition, moral judgement and moral intention were analysed using correlation analyses. The correlation analyses (see Table 1$)$ indicated that PEI $(0.088, p>0.05)$ and CAI $(0.041, p>0.05)$ were not correlated with MI. CUI was found to have a significant correlation only with MI $(0.237$, $p<0.01$ ). These results provided support for $\mathrm{H} 1, \mathrm{H} 2$ and $\mathrm{H} 3$.

When compared with intuition, MI had much stronger results. Perceived MI was found to be strongly correlated with moral recognition $(0.319, p>0.01)$, moral judgement (0.455, $p<0.01)$ and moral intention $(0.306 ; p<0.01)$. Therefore, the results supported $\mathrm{H} 4.1,4.2$ and $\mathrm{H} 4.3$.

In addition, Table 2 shows that PEI, CAI and CUI have no significant relationship with moral recognition, moral judgement and moral intention.

\section{Regression}

To further validate the results, regression analysis using the three kinds of intuition (PEI, CAI and CUI) as independent

TABLE 2: Correlations.

\begin{tabular}{|c|c|c|c|c|c|c|c|}
\hline Variable & $\begin{array}{c}\text { Personal experience } \\
\text { intuition (PEI) }\end{array}$ & $\begin{array}{c}\text { Collective archetype } \\
\text { intuition (CAI) }\end{array}$ & $\begin{array}{l}\text { Collective universal } \\
\text { intuition (CUI) }\end{array}$ & Moral intensity & Moral recognise & Moral judgement & Moral intention \\
\hline $\begin{array}{l}\text { Personal experience } \\
\text { intuition }\end{array}$ & 1 & - & - & - & - & - & - \\
\hline $\begin{array}{l}\text { Collective archetype } \\
\text { intuition }\end{array}$ & $0.494(0.000 * * *)$ & 1 & - & - & - & - & - \\
\hline $\begin{array}{l}\text { Collective universal } \\
\text { intuition }\end{array}$ & $\begin{array}{c}0.310 \\
(0.000 * * *)\end{array}$ & $\begin{array}{c}0.341 \\
\left(0.000^{* * *}\right)\end{array}$ & 1 & - & - & - & - \\
\hline Moral intensity & $\begin{array}{c}0.088 \\
(0.275)\end{array}$ & $\begin{array}{c}0.041 \\
(0.612)\end{array}$ & $\begin{array}{c}0.237 \\
(0.003 * *)\end{array}$ & 1 & - & - & - \\
\hline Moral recognition & $\begin{array}{l}-0.085 \\
(0.288)\end{array}$ & $\begin{array}{l}-0.007 \\
(0.927)\end{array}$ & $\begin{array}{l}-0.089 \\
(0.268)\end{array}$ & $\begin{array}{c}0.319 \\
(0.000 * * *)\end{array}$ & 1 & - & - \\
\hline Moral judgement & $\begin{array}{c}0.001 \\
(0.992)\end{array}$ & $\begin{array}{l}0.047 \\
(0.562)\end{array}$ & $\begin{array}{l}-0.037 \\
(0.644)\end{array}$ & $\begin{array}{c}0.455 \\
(0.000 * * *)\end{array}$ & $\begin{array}{c}0.269 \\
\left(0.001^{* *}\right)\end{array}$ & 1 & - \\
\hline Moral intention & $\begin{array}{l}-0.052 \\
(0.516)\end{array}$ & $\begin{array}{c}0.014 \\
(0.865)\end{array}$ & $\begin{array}{l}-0.029 \\
(0.715)\end{array}$ & $\begin{array}{c}0.306 \\
(0.000 * * *)\end{array}$ & $\begin{array}{c}0.168 \\
\left(0.036^{*}\right)\end{array}$ & $\begin{array}{c}0.229 \\
(0.004 * *)\end{array}$ & 1 \\
\hline
\end{tabular}

$N=157 ;{ }^{*} p<0.05 ;{ }^{* *} p<0.01 ;{ }^{* * *} p<0.001$ 
TABLE 3: Regression of personal experience intuition, collective archetype intuition and collective universal intuition on moral intensity.

\begin{tabular}{lccc}
\hline $\begin{array}{l}\text { Independent } \\
\text { variable }\end{array}$ & $\begin{array}{c}\text { Personal } \\
\text { experience } \\
\text { intuition }\end{array}$ & $\begin{array}{c}\text { Collective } \\
\text { archetype } \\
\text { intuition }\end{array}$ & $\begin{array}{c}\text { Collective } \\
\text { universal } \\
\text { intuition }\end{array}$ \\
\hline Standard coefficient (Beta) & 0.008 & 0.002 & 0.237 \\
$R^{2}$ & 0.008 & 0.002 & 0.056 \\
Adjusted $R^{2}$ & 0.001 & -0.005 & 0.050 \\
$F$-value & 1.203 & 0.259 & 9.249 \\
$p$-value & 0.275 & 0.612 & $0.003 * *$ \\
\hline
\end{tabular}

$* p<0.05, * * p<0.01, * * * p<0.001$.

TABLE 4: Regression of moral intensity on moral recognition, moral judgement and moral intention.

\begin{tabular}{lccc}
\hline $\begin{array}{l}\text { Moral intensity } \\
\text { (independent } \\
\text { variable) }\end{array}$ & $\begin{array}{c}\text { Moral recognition } \\
\text { (dependent } \\
\text { variable) }\end{array}$ & $\begin{array}{c}\text { Moral judgement } \\
\text { (dependent } \\
\text { variable) }\end{array}$ & $\begin{array}{c}\text { Moral intention } \\
\text { (dependent variable) }\end{array}$ \\
\hline $\begin{array}{l}\text { Standard } \\
\text { coefficient (Beta) }\end{array}$ & 0.333 & 0.455 & 0.306 \\
$R^{2}$ & 0.139 & 0.207 & 0.094 \\
Adjusted $R^{2}$ & 0.128 & 0.202 & 0.088 \\
$F$-value & 12.411 & 40.543 & 16.052 \\
$p$-value & $0.000^{* * *}$ & $0.000^{* * *}$ & $0.000^{* * *}$ \\
\hline
\end{tabular}

${ }^{*} p<0.05 ; * * p<0.01 ; * * * p<0.001$

variables was conducted on MI (dependent variable). However, the regression models for the MI measurements were not found to be statistically significant for PEI or CAI. The $F$ scores were not significant $(\mathrm{PEI}=1.203, p=0.275$; $\mathrm{CAI}=0.259, p=0.612)$, and no beta values were statistically significant for these two intuition types. However, for CUI and $\mathrm{MI}$, the $\mathrm{F}$ score was found to be significant (CUI = 9.249, $p=0.003$ ), with a significant beta value of 0.237 . Therefore, H1, H2 and H3 were supported (Table 3).

A statistical significance was observed for the measure of MI on moral recognition, moral judgement and moral intention. The $F$ scores for the models were found to have statistical significance (moral recognition $=12.411, p=0.000$; moral judgement $=40.543, p=0.000$; moral intention $=$ $16.052, p=0.000)$; all beta values for the measurements with regard to moral recognition, moral judgement and moral intention were found to be statistically significant $(0.333$, 0.455 and 0.306). Therefore, H4.1, H4.2 and H4.3 are supported (Table 4).

\section{Testing the model of collective universal intuition}

The model was further examined using SEM techniques employing AMOS software. The results of the SEM for CUI indicated that the model had a good fit $\left(\chi^{2}=85.040\right.$; $\mathrm{df}=42$; $\chi^{2} / \mathrm{df}=2.025 ; \mathrm{GFI}=0.916 ; \mathrm{AGFI}=0.869 ; \mathrm{PNFI}=0.624 ; \mathrm{CFI}=$ $0.895 ; \mathrm{RMR}=0.077 ; \mathrm{RMSEA}=0.081) . \chi^{2} / \mathrm{df}(2.025)$ was lower than 3. In addition, GFI (0.916), AGFI (0.869) and PNFI (0.624) were, respectively, above $0.9,0.8$ and 0.5 , which were within the suggested index (Schumacker \& Lomax 2010). A comparative fit index (CFI) (Bentler 1989) of 0.895 indicates a good fit; therefore, the model performed well (Figure 1).

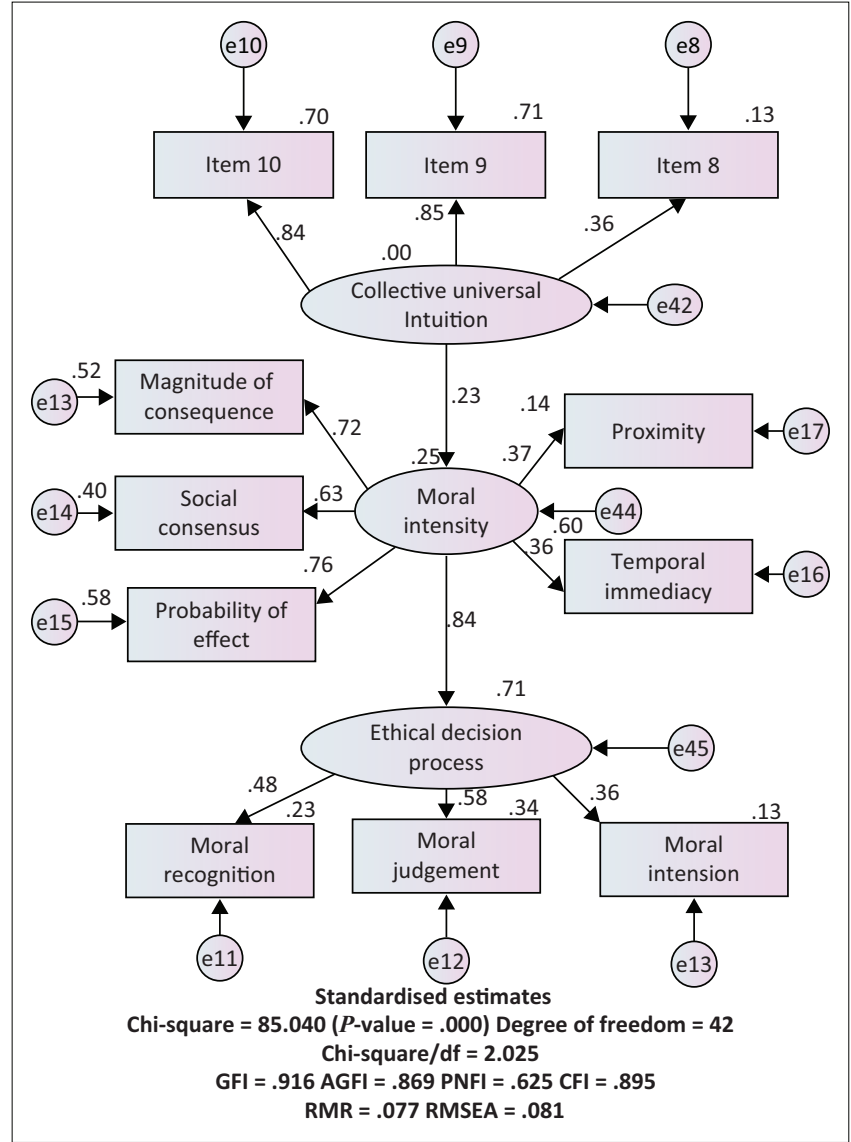

FIGURE 1: Structural equation model for collective universal intuition.

\section{Testing a rival model}

An emerging consensus in structural equations modelling is the use of comparative rival models (Bollen \& Long 1992). The extremely parsimonious model used in the current study posited that only CUI would be positively associated with MI, implying a nomological status for PEI and CAI. This study compared (see Table 5) the CUI model with two rival models, using the following criteria: (1) overall fit of the model implied a covariance matrix to the sample covariance matrix as measured by the CFI; (2) the models' hypothesised parameters that were statistically significant; and (3) parsimony, as measured by PNFl (James, Mulaik \& Brett 1982).

In addition, GFI is a measure of fit between the hypothesised model and the observed covariance matrix. Goodness-of-fit index between 0 and 1 , with a value above 0.8 , generally indicates acceptable model fit (Bollen \& Long 1992). In the present study, because the GFI for the three models (CUI, PEI and CAI) are $0.916,0.884$ and 0.923 , respectively, all the models are a good fit.

Because the model fit indexes of the three models were similar, the CUI model and the two rival models performed well. For the paths from each intuition to MI, only the estimate for the path from CUI to MI was found to be significant (Critical ratio [C.R.] $=0.23 ; p=0.018<0.05$ ), which implied that CUI had a significant effect on MI; therefore, H3 was supported. However, the estimates from rival model 1 
TABLE 5: Analysis of competing structural models.

\begin{tabular}{|c|c|c|c|}
\hline $\begin{array}{l}\text { Author to provide } \\
\text { heading }\end{array}$ & $\begin{array}{l}\text { CUI model: } \\
\text { Hypothesis } 3\end{array}$ & $\begin{array}{l}\text { Rival model 1: } \\
\text { Hypothesis } 1\end{array}$ & $\begin{array}{l}\text { Rival model 2: } \\
\text { Hypothesis } 2\end{array}$ \\
\hline 4 & & & \\
\hline \multirow[t]{2}{*}{ Estimate } & $\begin{array}{l}\text { Collective Universal } \\
\text { Intuition } \rightarrow \text { Moral } \\
\text { intensity }\end{array}$ & $\begin{array}{l}\text { Personal Experience } \\
\text { Intuition } \rightarrow \text { Moral } \\
\text { intensity }\end{array}$ & $\begin{array}{l}\text { Collective Archetype } \\
\text { Intuition } \rightarrow \text { Moral } \\
\text { intensity }\end{array}$ \\
\hline & $\begin{array}{l}\text { C.R. }=0.23 * \\
(p=0.018<0.05)\end{array}$ & $\begin{array}{l}\text { C.R. }=0.03 \\
(p=0.757>0.05)\end{array}$ & $\begin{array}{l}\text { C.R. }=0.04 \\
(p=0.739>0.05)\end{array}$ \\
\hline \multirow[t]{2}{*}{ Estimate } & $\begin{array}{l}\text { Moral intensity } \rightarrow \\
\text { Ethical decision } \\
\text { process }\end{array}$ & $\begin{array}{l}\text { Moral intensity } \rightarrow \\
\text { Ethical decision } \\
\text { process }\end{array}$ & $\begin{array}{l}\text { Moral intensity } \rightarrow \\
\text { Ethical decision } \\
\text { process }\end{array}$ \\
\hline & $\begin{array}{l}\text { C.R. }=0.84^{*} \\
(p=0.01<0.05)\end{array}$ & $\begin{array}{l}\text { C.R. }=0.86^{*} \\
(p=0.018<0.05)\end{array}$ & $\begin{array}{l}\text { C.R. }=0.86^{*} \\
(p=0.019<0.05)\end{array}$ \\
\hline$\chi^{2}$ & 85.040 & 110.369 & 70.821 \\
\hline$\chi^{2} / d f$ & 2.205 & 2.122 & 1.686 \\
\hline GFI & 0.916 & 0.884 & 0.923 \\
\hline AGFI & 0.869 & 0.826 & 0.879 \\
\hline PNFI & 0.624 & 0.630 & 0.610 \\
\hline CFI & 0.895 & 0.879 & 0.903 \\
\hline RMR & 0.077 & 0.071 & 0.055 \\
\hline RMSEA & 0.081 & 0.085 & 0.066 \\
\hline
\end{tabular}

CUI, Collective Universal Intuition; PEI, Personal Experience Intuition; CAl, Collective Archetype Intuition; MI, Moral intensity; ED, Ethical decision process; C.R.: critical ration (i.e. $t$-value).

${ }^{*} p<0.05, * * p<0.01,{ }^{* * *} p<0.001$

(C.R. $=0.03, p=0.757>0.05)$ and rival model 2 (C.R. $=0.04$ $p=0.739>0.05)$ were not found to be significant, implying that neither PEI nor CAI had any effect on MI; therefore, Hypotheses 1 and 2 were supported.

The estimates for the path from MI to the ethical decision process for the three models were, respectively, $0.84,0.86$ and 0.86 . This means that MI has a positive effect on the ethical decision process.

\section{Discussion and implications Theoretical implications}

The main purpose of this study was to investigate the association between intuition and EDM. From the results of the correlation, regression and SEM analyses, no statistically significant correlations were found between PEI and CAI and MI from the scenario-based survey of 157 spirit mediums. It is important, however, to recognise that CUI was found to have a statistically positive association with MI. This finding implied that only pure intuition (i.e. CUI) has a positive association with EDM. This finding suggests that because previous studies failed to find pure intuition, they were not able to find the difference in intuitive processing.

Another positive finding of this research was the confirmation of the variables that measured MI. Similar to previous findings by Morris and McDonald (1995), Singhapakdi et al. (1996) and Ayoun et al. (2015), it was found that moral recognition, moral judgement and moral intention were significantly correlated with the five perceived MI factors,
TABLE 6: Development of intuition and the stages involved.

\begin{tabular}{lll}
$\begin{array}{l}\text { The stage of intuition } \\
\text { development }\end{array}$ & Moral intuition & $\begin{array}{l}\text { Suitable approach for } \\
\text { ethical decision-making }\end{array}$ \\
\hline $\begin{array}{l}\text { Step 1: Personal experience } \\
\text { intuition (PEI) }\end{array}$ & $\begin{array}{l}\text { There is no moral } \\
\text { intuition. }\end{array}$ & $\begin{array}{l}\text { Rational approach (Jones 1991; } \\
\text { Rest 1986; Trevino 1986) }\end{array}$ \\
$\begin{array}{l}\text { Step 2: Collective archetype } \\
\text { intuition (CAI) }\end{array}$ & $\begin{array}{l}\text { There is no moral } \\
\text { intuition. }\end{array}$ & $\begin{array}{l}\text { Integrated approach (Schwartz } \\
\text { 2016; Vasconcelos 2009; } \\
\text { Woiceshyn 2011) }\end{array}$ \\
$\begin{array}{ll}\text { Step 3: Collective universal } \\
\text { intuition (CUI) }\end{array}$ & $\begin{array}{l}\text { There is moral } \\
\text { intuition. }\end{array}$ & $\begin{array}{l}\text { Intuitionist approach (Haidt } \\
\text { 2001; Sonenshein 2007) }\end{array}$ \\
\hline
\end{tabular}

providing more evidence to support Jones's (1991) concept of MI. These findings were encouraging because they provide a method with a psychological and empirical foundation for the evaluation of ethical situations for future management research.

\section{Practical implications}

This article defines moral intuition as a type of spontaneous and possibly unforeseeable evaluation that typically occurs 'at the fringe of consciousness'. It may not involve direct evaluation or the critical examination of evidence; however, it is nonetheless capable of exerting meaningful influence on ethical judgements and moral decision-making (Haidt \& Bjourklun 2008).

On the basis of the results of this empirical test, a framework to assess the stages of intuition development has been created. In the PEI stage, intuition is not empirically associated with MI, which may indicate that there is no moral intuition. Because the personal unconscious lacks moral intuition, a rationalist EDM approach seems to be necessary.

In the CAI stage as well, the results indicated that intuition is not associated with MI. Therefore, an integrated EDM approach may be a good choice as each approach triggers moral intuition by adopting a proposed method, such as by praying, through rational egoism or through personal moral capacity.

In the CUI stage, intuition was found to be associated with MI, indicating the presence of moral intuition. Table 6 shows the various stages of intuition development. At the PEI and CAI levels, there is no moral intuition. At the CUI level, however, moral intuition was found to be present.

\section{Limitations and future research}

An investigation into the relationship between intuition and EDM is a difficult endeavour as they are inevitably constrained by numerous limitations. The different definitions of intuition limit the measurement and comparability of the results of the present study with those of similar research. In addition, research into the dynamic associations between intuition and EDM can be approached using various research questions, designs and hypotheses. The results of this study, therefore, require careful interpretation to ensure that overreaching conclusions are avoided.

This study did not capture the full range of the relevant ethical concerns because only one scenario was adopted in 
the analysis, which could cause a probable unintended bias towards the Taiwanese context. In addition, because most respondents were Taiwanese, this must be considered when interpreting the results. Including different cultural and religious background variables in future research may improve the ability to more fully understand the nuances underlying the intuitional influences on the EDM process.

\section{Conclusion}

Much work has been conducted already to examine the association between intuition and EDM. Although the relationship between intuition and ethics may seem to be intuitively positive, empirical studies of these assumptions have produced controversial results. This study aims to examine whether intuition is associated with the MI of EDM processes, by surveying professional spirit mediums. The findings indicated that only universal collective intuition has a significant effect on EDM, which suggests that a pure mind can improve the decision-making process. In light of these findings, it seems clear that decision-makers would benefit by being more attuned to their sense of morality.

This study has not completely addressed the deficiencies related to CUI. However, if a new CUI theoretical model can consider the primary concern raised by this finding, a more robust model may be developed.

\section{Acknowledgements}

The authors thank the Taiwan Mediums' Association in particular for their support of this research work.

\section{Competing interests}

The authors declare that they have no financial or personal relationship(s) that may have inappropriately influenced them in writing this article.

\section{Authors' contributions}

All authors conceived the idea for this article, which is based on their research. Although the first author, J.S.L., took the lead in writing, data collecting and analysing, all authors contributed substantially to the final manuscript.

\section{References}

Allinson, C.W. \& Hayes, J., 1996, 'The cognitive style index: A measure of intuitionanalysis for organizational research', Journal of Management Studies 33(1), 119-135. https://doi.org/10.1111/j.1467-6486.1996.tb00801.x

Arnold, D.G., Goodpaster, K.E. \& Weaver, G.R., 2016, 'Celebrating our 25th anniversary: BEQ's past trends and future', Business Ethics Quarterly 25, v-vii.

Ayoun, B., Rowe, L. \& Yassine, F., 2015, 'Is workplace spirituality associated with business ethics?' International Journal of Contemporary Hospitality Management 27(5), 938-957. https://doi.org/10.1108/IJCHM-01-2014-0018

Babakus, E. \& Mangold, W.G., 1992, 'Adapting the SERVQUAL scale to hospital services: An empirical investigation', Health Services Research 26(6), 767-786.

Badiane, K., 2015, 'Intuitive judgement: A vigilant market learning capacity'. Doctoral dissertation, Feng Chia University, Taiwan.

Barbour, I.G., 2014, 'Zygon's dual mission', Zygon ${ }^{\circledR}$ 49(1), 81-94. https://doi. org/10.1111/zygo.12060

Bargh, J.A., 2005, 'Bypassing the will: Toward demystifying the nonconscious control of social behaviour', in R.R. Hassin, J.S. Uleman \& J.A. Bargh (eds.), The new unconscious, vol. 12, pp. 37-60, ISBN9780195307696, Oxford University Press, Oxford.
Barnard, C.I., 1938, The functions of the executive, Harvard University Press, Cambridge, MA.

Becker, G.S., 1976, The economic approach to human behaviour, University of Chicago Press, Chicago, IL.

Bentler, P.M., 1989, EQS structural equations program manual, BMDP, Los Angeles, CA.

Bollen, K.A. \& Long, J.S., 1992, 'Tests for structural equation models', Sociological Methods and Research 21(2), 123-131. https://doi.org/10.1177/0049124192021002001

Boomsama, A., 1982, 'The robustness of LISREL against small sample size in factor analysis models', in H. Wold \& K. Joreskog (eds.), Systems under indirection observation, pp. 149-173, Elsevier/North-Holland, New York.

Campbell, D.T. \& Stanley, J.C., 1963, Experimental and quasi-experimental designs for research, Houghton Mifflin, Dallas, TX.

Campbell, J. (rd)., 1971, The portable Jung, transl. R.F.C. Hull, Penguin Books, New York. Clart, P., 2003, 'Moral mediums', Ethnologies 25(1), 153. https://doi.org/10.7202/007129ar

Cline, E.M., 2010, 'Female spirit mediums and religious authority in contemporary Southeastern China', Modern China 36(5), 520-555. https://doi.org/10.1177/ 0097700410372921

Dawes, D., 2008, 'Do data characteristics change according to the number of scale points used. An experiment using 5-point, 7-point and 10-point scales', International Journal of Market Research 50(1), 61-77. https://doi. org/10.1177/147078530805000106

Ding, L., Velicer, W.F. \& Harlow, L.L., 1995, 'Effect of estimation methods, number of indicators per factor, and improper solutions on structural equation modeling fit indices', Structural Equation Modeling: A Multidisciplinary Journal 2(2), 119-143. https://doi.org/10.1080/10705519509540000

Dornoff, R.J. \& Tankersley, C.B., 1975, 'Perceptual differences in market transactions: A source of consumer frustration', Journal of Consumer Affairs 9(1), 97-103. https:// doi.org/10.1111/j.1745-6606.1975.tb00553.x

Dutton, D., 2010, The art instinct: Beauty, pleasure, and human evolution, Oxford University Press, Oxford.

Eliade, M., 1964, Shamanism: Archaic techniques of ecstasy, transl. R.T. Willard, Princeton University Press, Princeton, NJ.

Ellenberger, H.F., 1970, The discovery of the unconscious: The history and evolution of dynamic psychiatry, Basic Books, New York.

Ellertson, C.F., Ingerson, M.C. \& Williams, R.N., 2016, 'Behavioural ethics: A critique and a proposal', Journal of Business Ethics 138(1), 145-159. https://doi. org/10.1007/s10551-015-2628-y

Fontein, J., 2006, 'Shared legacies of the war: Spirit mediums and war veterans in Southern Zimbabwe', Journal of Religion in Africa 36(2), 167-199. https://doi. org/10.1163/157006606777070687

Foot, P., 1967, 'The problem of abortion and the doctrine of double effect', Oxford Review 5, 5-15.

Fu, F.L. \& Yen, H.C., 2002, 'Marketing EDM by information service enterprises', MIS Review 12, 31-59.

Giacalone, R.A. \& Jurkiewicz, C.L., 2003, 'Right from wrong: The influence of spirituality on perceptions of unethical business activities', Journal of Business Ethics 46(1) 85-97. https://doi.org/10.1023/A:1024767511458

Gigerenzer, G., 2008, 'Moral intuitions = fast and frugal heuristics?', in W. Sinnott-Armstrong (ed.), The cognitive science of morality: Intuition and diversity. Moral psychology, vol. 2, pp. 1-26, ISBN9780262303002, MIT Press, Cambridge, MA.

Goleman, D., Kaufman, P. \& Ray, M.L., 1992, The creative spirit, Penguin, New York.

Groesbeck, C.J., 1989, 'C. G. Jung and the Shaman's vision', Journal of Analytical Psychology 34, 255-275.

Guzak, J.R., 2009, 'The role of intuition in EDM', Dissertation for the degree of philosophy, University of Texas, Arlington, TX.

Haidt, J., 2001, 'The emotional dog and its rational tail: A social intuitionist approach to moral judgement', Psychological Review 108, 814-834. https://doi. org/10.1037/0033-295X.108.4.814

Haidt, J. \& Bjorklund, F., 2008, 'Social intuitionists answer six questions about moral psychology', in W. Sinnott-Armstrong (ed.), Moral psychology: The cognitive science of morality: Intuition and diversity, 181-217, MIT Press, Cambridge, MA. ISBN 9780262303002.

Hair, J.F., Black, W.C., Babin, B.J., Anderson, R.E. \& Tatham, R.L., 1992, Multivariate data analysis with reading, 3rd edn., Macmillan, New York.

Henry, P.J., 2008, 'College sophomores in the Laboratory Redux: Influences of a narrow Data Base on social psychology's view of the nature of prejudice', Psychological Inquiry 19(2), 49-71. https://doi.org/10.1080/10478400802049936

Hunt, S.D. \& Vitell, S., 1986, 'A general theory of marketing ethics', Journal of Macromarketing 6(1), 5-16. https://doi.org/10.1177/027614678600600103

James, L.R., Mulaik, S.A. \& Brett, J., 1982, Causal analysis: Models, assumptions, and data, Sage, Newbury Park, CA.

Jones, T.M., 1991, 'Ethical decision-making by individuals in organizations: An issuecontingent model', Academy of Management Review 16(2), 366-395. https://doi. org/10.5465/amr.1991.4278958

Jung, C.G., 1921 [1923], Psychological types, transl. P. Typen \& Z. Rascher, Kegan Paul, London. 
Jung, C.G., 1936 [1969], Psychological factors determining human behaviour in Collected Works, vol. 8, pp. 114-125, Princeton University Press, Princeton, NJ.

Jung, C.G., 1969, Aion, collected works, vol. 9ii, Princeton University, Princeton, NJ.

Jung, C.G., 1981, Archetypes and the collective unconscious in Collected Works, vol. 9 Princeton University Press, Princeton, NJ.

Jung, C.G., 1989, Memories, dreams, reflections, A. Jaffe (ed.), Fontana Press, London

Kahneman, D., 2003, 'A perspective on judgement and choice: Mapping bounded rationality', American Psychologist 58, 697-720.

Kant, I., 1790 [1952], Critique of judgement, transl. J.C. Meridith, Oxford University Press, Oxford.

Kennedy, E.J. \& Lawton, L., 1998, 'Religiousness and business ethics', Journal of Business Ethics 17(2), 163-175. https://doi.org/10.1023/A:1005747511116

Kline, R.B., 2011, Principles and practices of structural equation modeling, 2nd edn., Guilford, New York.

Kohlberg, L., 1971, 'Stages of moral development as a basis for moral education', in C.M. Beck, B.S. Crittenden \& E.V. Sullivan (eds.), Moral education: in C.M. Beck, B.S. Crittenden \& E.V. Sullivan (eds.), Moral education: ISBN10:0809117568.

Kohlberg, L., 1973, 'The claim to moral adequacy of a highest stage of moral judgement', The Journal of Philosophy 70(18), 630-646. https://doi.org/10.2307/2025030

Loehlin, J.C., 2004, Latent variable models: An introduction to factor, path, and structural analysis, 4th edn., Lawrence Erlbaum, Hillsdale, NJ.

Marshall, I.N., 1968, 'The four functions: A conceptual analysis', Journal of Analytical Psychology 13(1), 1-32. https://doi.org/10.1111/j.1465-5922.1968.00001.x

McCoach, D.B., Black, A.C. \& O'Connell, A.A., 2007, 'Errors of inference in structural equation modeling', Psychology in the Schools 44(5), 461-470.

Mikhail, J., 2007, 'Universal moral grammar: Theory, evidence and the future', Trend in Cognitive Sciences 11(4), 143-152. https://doi.org/10.1016/j.tics.2006.12.007

Monin, B., Pizarro, D.A. \& Beer, J.S., 2007, 'Deciding versus reacting: Conceptions of moral judgement and the reason-affect debate', Review of General Psychology 11(2), 99-111. https://doi.org/10.1037/1089-2680.11.2.99

Morris, S.A. \& McDonald, R.A., 1995, 'The role of moral intensity in moral judgements: An empirical investigation', Journal of Business Ethics 14(9), 715-726. https://doi. org/10.1007/BF00872325

Nunnally, J.C., 1978, Psychometric theory, 2nd edn., McGraw-Hill, New York.

Paper, J., 1995, The spirits are drunk: Comparative approaches to Chinese religion SUNY Press, Albany, NY.

Paper, J., 1996, 'Mediums and modernity: The institutionalization of ecstatic religious functionaries in Taiwan', Journal of Chinese Religions 24(1), 105-129. https://doi. functionaries in Taiwan', Journal of Chin
$\mathrm{org} / 10.1179 / 073776996805307120$

Peterson, R.A., 2001, 'On the use of college students in social science research Insights from a second-order meta-analysis', Journal of Consumer Research 28(3), 450-461. https://doi.org/10.1086/323732

Pilard, N., 2015, Jung and intuition: On the centrality and variety of forms of intuition in Jung and Post-Jungians, Karbac Books Ltd., London.

Raines-Eudy, R., 2000, 'Using structural equation modeling to test for differentia reliability and validity: An empirical demonstration', Structural Equation Modeling: A Multidisciplinary Journal 7(1), 124-141. https://doi.org/10.1207/ S15328007SEM0701_07

Rest, J.R., 1986, Moral development: Advances in research and theory, Praeger New York.

Ruff, J., 2000, 'Skeletal muscle sodium current is reduced in hypokalemic periodic paralysis. US: Hays (Nicolas) Ltd', Proceedings of the National Academy of Sciences paralysis. US: Hays (Nicolas) Ltd', Proceedings of the National Acad
97(18), 9832-9833. https://doi.org/10.1073/pnas.170293197

Sauer, H., 2012, 'Educated intuitions, automaticity and rationality in moral judgement', Philosophical Explorations 15(3), 255-275. https://doi.org/10.1080/13869795.20 12.706822

Schumacker, R.E. \& Lomax, R.G., 2010, A beginner's guide to structural equation modeling, 2nd edn., Lawrence Erlbaum Associates, Mahwah, NJ.

Schwartz, M.S., 2016, 'EDM theory: An integrated approach', Journal of Business Ethics 169, 755-756. https://doi.org/10.1007/s10551-015-2886-8

Sears D.O., 1986, 'College sophomores in the laboratory: Influences of a narrow data base on social psychology's view of human nature', Journal of Personality and Social Psychology 51(3), 515-530. https://doi.org/10.1037/0022 3514.51.3.515

Shamdasani, S. (transl.), 2009, Jung. C.G. Liber Novus (The New Book), W W Norton \& Company, New York.

Sharma, S., 1996, Applied multivariate techniques, John Wiley, New York.

Shaw, T.R., 2003, 'The moral intensity of privacy: An empirical study of webmasters attitudes', Journal of Business Ethics 46(4), 301-318. https://doi. org/10.1023/A:1025628530013

Shyu, C.S., Li, Y.L. \& Tang, Y., 2013, 'Applying confirmatory factor analysis on the measure for restaurant over-service', Journal of International Management Studies 8(2), 10-16.

Simon, H.A., 1992, 'What is an explanation of behaviour?' American Psychological Society 3(3), 150-161.

Singhapakdi, A., Vitell, S.J. \& Kraft, K.L., 1996, 'Moral intensity and EDM of marketing professionals', Journal of Business Research 36(3), 245-255. https://doi.org/ 10.1016/0148-2963(95)00155-7

Sonenshein, S., 2007, 'The role of construction, intuition, and justification in responding to ethical issues at work: The sensemaking-intuition model', Academy of Management Review 32(4), 1022-1040. https://doi.org/10.5465/amr.2007.26585677

Sparks, J.R. \& Pan, Y., 2010, 'Ethical judgements in business ethics research: Definition, and research agenda', Journal of Business Ethics 91(3), 405-418. https://doi. org/10.1007/s10551-009-0092-2

Sultania, N., Kunwar, N., Chaudhary, A. \& Yadav, P.S., 2012, 'Effect of society parameters on adolescents in depression and increase the suicide rate in India', Indian Journal of Social Research 53(3), 243-248.

Sustain, C.R., 2005, 'Moral heuristics', Behavioral and Brain Sciences 28(4), 531-573.

Sutton, D., 1989, 'Ritual trance and the social order: The persistence of Taiwanese shamanism', in A.E. Barnes \& P.N. Stearns (eds.), Social history and issues in consciousness: Some interdisciplinary connections, pp. 108-127, New York University, New York.

Sutton, D., 1990, 'Rituals of self-mortification: Taiwanese spirit mediums in comparative perspective', Journal of Ritual Studies 4(1), 99-125.

Sutton, D., 2003, Steps of perfection: Exorcistic performers and Chinese religion in twentieth-century Taiwan, Harvard University, Cambridge, MA

Tinghög, G., Andersson, D., Bonn, C., Johannesson, M., Kirchler, M., Koppel, L. et al., 2016, 'Intuition and moral decision-making-the effect of time pressure and cognitive load on moral judgement and altruistic behaviour', PLoS One 11 e0164012. https://doi.org/10.1371/journal.pone.0164012

Trevino, L.K., 1986, 'Ethical decision-making in organizations: A person-situation interactionist model'. Academy of Management Review 11(3), 601-617. https:// doi.org/10.5465/amr.1986.4306235

Tribodeau, L., 2009, Natural-born intuition: How to awaken and develop your inner wisdom, The Career Press, New Jersey.

Tsai, Y.J., 2004, 'The writing of history: The religious practices of the mediums' association in Taiwan', Taiwan Journal of Anthropology 2(2), 43-80.

Valentine, S. \& Fleischman, G., 2003, 'Moral reasoning in an equitable relie innocent spouse context', Journal of Business Ethics 45(4), 325-339. https://doi. org/10.1023/A:1024111814533

Vasconcelos, A.F., 2009, 'Intuition, prayer, and managerial decision-making processes: A religion-based framework', Management Decision 47(6), 930-949. https://doi. org/10.1108/00251740910966668

Vizczino, V.M., Martínez, M.S., Aguilar, F.S., Martínez, S.S., Gutiérrez, R.F., López, M.S. et al., 2010, 'Validity of a single-factor model underlying the metabolic syndrome in children', Diabetes Care 33(6), 1370-1372. https://doi. org/10.2337/dc09-2049

Weick, K.E., 1995, Sensemaking in organizations, Sage, Thousand Oaks, CA.

Woiceshyn, J., 2011, 'A model for ethical decision making in business: Reasoning, intuition, and rational moral principles', Journal of Business Ethics 104(3), 311-323. https://doi.org/10.1007/s10551-011-0910-1

Young, E.P. \& Dawson, T., 1997, The Cambridge companion to Jung, Cambridge University Press, Cambridge.

Zheng, Z., 2016, 'The spirit world outlooks and religious missions of spirit-mediums in Taiwan', New Century Religions Studies 14(3), 1-32. 


\section{Appendix 1}

Table 1-A1: Questionnaire content.

\begin{tabular}{|c|c|c|c|c|c|}
\hline Construct $N$ & Content: all are five-point Likert-type scales & $\begin{array}{c}\text { Factor } \\
\text { loading }\end{array}$ & $\begin{array}{l}\text { Composite } \\
\text { reliability }\end{array}$ & $\begin{array}{c}\text { Cronbach's } \\
\alpha\end{array}$ & Concept Source \\
\hline \multicolumn{6}{|c|}{ Personal experience intuition (PEI) } \\
\hline 1 & I make many of my decisions on the basis of intuition. & 0.717 & \multirow{3}{*}{0.805} & \multirow{3}{*}{0.801} & Allinson and Hayes (1996) \\
\hline 3 & I am hardly ever wrong when I listen to my deepest gut feelings to find the answer. & 0.697 & & & Badiane (2015) \\
\hline 4 & I trust my gut when faced with exceptional circumstances. & 0.630 & & & Badiane (2015) \\
\hline \multicolumn{6}{|c|}{ Collective archetype intuition (CAI) } \\
\hline 6 & $\begin{array}{l}\text { When I follow my intuition to propose an idea, it is easy for the discussion to gain } \\
\text { communal assent. }\end{array}$ & 0.592 & \multirow[t]{2}{*}{0.534} & \multirow[t]{2}{*}{0.519} & $\begin{array}{l}\text { Badiane (2015) Kant (1790 } \\
\text { [1952]) }\end{array}$ \\
\hline 7 & I understand that my internal voice is from a deity or my ego. & 0.579 & & & Own statement \\
\hline \multicolumn{6}{|c|}{ Collective universal intuition (CUI) } \\
\hline 8 & I get a deity's guidance by hearing a sound & 0.896 & \multirow{3}{*}{0.824} & \multirow{3}{*}{0.686} & Jung (1989) \\
\hline 9 & I get a deity's guidance by seeing a vision & 0.778 & & & Jung (1989) \\
\hline 10 & My creative solutions come without reaching conscious awareness & 0.657 & & & $\begin{array}{l}\text { Badiane (2015) } \\
\text { Goleman, Kaufman and } \\
\text { Ray (1992) }\end{array}$ \\
\hline \multicolumn{6}{|c|}{ Moral recognition } \\
\hline 11 & I think that this story involves an ethical perception & - & & & - \\
\hline \multicolumn{6}{|c|}{ Moral judgement } \\
\hline 12 & I think Li's demands are immoral & - & & & - \\
\hline \multicolumn{6}{|c|}{ Moral Intensity } \\
\hline 13 & I think Li's demands will cause great harm to Zhang's wife and children & 0.711 & \multirow{5}{*}{0.756} & \multirow{5}{*}{0.743} & Magnitude of consequence \\
\hline 14 & I think Li's demands cannot be accepted by the society & 0.605 & & & Social consensus \\
\hline 15 & I think Li's demands is likely to cause a family tragedy & 0.773 & & & Probability of effect \\
\hline 16 & I think Li's request will cause immediate & 0.630 & & & Temporal \\
\hline & damage to the relevant parties & & & & immediacy \\
\hline 17 & I have a deep aversion to Li's demands & 0.339 & & & Proximity \\
\hline \multicolumn{6}{|c|}{ Moral intention } \\
\hline 18 & In the above situation, I would not support Li's requests & - & & & - \\
\hline
\end{tabular}

Scenario: Miss Li, who is a young woman, was employed in a technology company as the boss's (Mr Zhang) secretary. She fell in love with Mr. Zhang and became pregnant with his child. Consequently, Li asked Zhang to marry her; however, Zhang was reluctant to make a decision. After she asked him to marry her, Miss Li became aware that Mr. Zhang was married and had a family. Miss Li asked for assistance so that she and Mr. Zhang could get married. The following questions are referenced from Dornoff and Tankersley (1975) and Jones (1991). 